\title{
Use of small and medium-sized water reservoirs by otters in a Mediterranean ecosystem
}

\author{
Mafalda P. Basto ${ }^{1,2, *}$, Nuno M. Pedroso ${ }^{2}$, António Mira ${ }^{1}$ and Margarida Santos-Reis ${ }^{2}$ \\ ${ }^{1}$ Universidade de Évora, Departamento de Biologia, Unidade de Biologia da Conservação, \\ Herdade da Mitra, Valverde, 7002-554 Évora, Portugal \\ ${ }^{2}$ Universidade de Lisboa, Centro de Biologia Ambiental/Departamento de Biologia Animal, \\ Faculdade de Ciências da Universidade de Lisboa, Edifício C2, Campo Grande, \\ 1749-016 Lisboa, Portugal
}

\begin{abstract}
Water is a limiting factor in Mediterranean regions, being specially important to aquatic species such as the Eurasian otter. The seasonal fluctuation of this resource is often addressed by constructing small and medium-sized water reservoirs. However, their role in the ecology and conservation of Eurasian otters is largely unknown. Our main goals were to assess the level of use of these reservoirs by otters and determine the main factors that may explain the observed levels of use. Intensity of use was determined by signs of otter presence and related to environmental variables using generalized linear models and variation partitioning techniques. Otters were present in the majority of reservoirs, both in the wet and dry seasons. Otter marking intensity was higher during the dry season, and positively associated with abundance of fish and American crayfish, existence of refuges and marking sites, number of watercourses and area of reservoir. In contrast, cattle settlements, annual crops and length of watercourses in the surrounding area negatively affected the use of the reservoirs. Otter diet reflected their opportunistic behaviour through the selection of seasonally available prey and corroborated the importance of American crayfish as a food item. Our results confirm that otters use the majority of small and medium-sized reservoirs in the study area. Despite this, reservoirs may be considered suboptimal habitats and seem to be specially relevant in the dry season, increasing water availability and acting as important feeding areas mainly when close to watercourses with good refuge conditions. Management implications are discussed.
\end{abstract}

(c) Koninklijke Brill NV, Leiden, 2011.

\section{Keywords}

Lutra lutra; habitat selection; diet; water reservoirs; Mediterranean region

\footnotetext{
*) Corresponding author; e-mail: mafalda.basto@gmail.com 